\title{
From the editors: Collaboration and the formation of new knowledge artifacts
}

\author{
Sten Ludvigsen • Gerry Stahl • Nancy Law • Ulrike Cress
}

Published online: 7 March 2015

(C) International Society of the Learning Sciences, Inc. 2015

To learn in our knowledge-oriented society often involves a deep engagement with knowledge artifacts - objects that combine material and semiotic aspects. This is particularly true in CSCL contexts. Knowledge can be formed and shared in different ways and within different formats.

Through advances in computer-supported collaborative learning technologies and pedagogies, we can create, shape and present knowledge in new ways. Intersubjective meanings can be developed and shared as virtual and/or physical artifacts. The nature of the collaboratively formed knowledge artifacts create specific opportunities for students or community participants to engage in certain types of interaction, both with the artifacts themselves and through them in collaborative efforts with peers, teachers and other actors. One way to express how knowing can be materially mediated is to state how the relationship between a conceptual structure and its material anchors creates special conditions for participant interaction and learning (Hutchins 2005).

Focus on the interpenetration of semantics and materiality is at the heart of the CSCL community's mission. We need to understand and explain how participants can become deeply engaged with mixes of conceptual and physical structures in their activities. In this issue of $i j C S C L$, these matters are addressed from the perspectives of several different theoretical frameworks. We introduce these articles by raising some overall themes about the formation of new knowledge artifacts in collaborative contexts.

Artifacts have been conceptualized within the CSCL community from cognitive, sociocognitive and socio-cultural stances. The term artifacts is often substituted with tools or

\author{
S. Ludvigsen \\ University of Oslo, Oslo, Norway \\ e-mail: Sten@ijCSCL.org \\ G. Stahl $(\bowtie)$ \\ Drexel University, Philadelphia, USA \\ e-mail: Gerry@ijCSCL.org \\ N. Law \\ University of Hong Kong, Hong Kong, China \\ e-mail: Nancy@ijCSCL.org \\ U. Cress \\ Knowledge Media Research Center, Tübingen, Germany \\ e-mail: Ulrike@ijCSCL.org
}


instruments (Lonchamp 2012; Ritella and Hakkarainen 2012), and many scholars use the term structuring resources or just resources to get a grasp of how participants perform their tasks (Arvaja 2012; Stahl 2012). This constellation of terms points to the fact that collaborative effort is interdependent with the artifacts that we use - in a bidirectional relationship. This does not necessarily mean that there is a causal relationship between collaboration and artifacts, but that we need to understand how the interdependencies can be played out or enacted. If particular artifacts can foster specific effects, we can conceptualize this as steps toward a causal understanding of mechanisms, although not in a mechanical or predictive manner.

Most theories in CSCL are constructivist in that they posit that learners actively construct their knowledge. However, this is often understood psychologically, as a mental process of representing knowledge in thoughts, mental schema, tacit know-how or practices. Scardamalia and Bereiter (2014) coined the term knowledge building that "treats ideas as entities in their own right that can have properties, connections and potentialities independent of the mental states of the individuals who hold the ideas" (p. 397). They thereby distinguish between learning as a change in mental state (e.g., from pre- to post-test) from knowledge building as the production of designs, theories, problem solutions, etc. Knowledge building centrally involves the formation and refinement of artifacts, such as texts, diagrams or models, which embody the knowledge as physical or virtual objects in the world.

The distinction between mental representations of knowledge and the building of knowledge through the refinement of artifacts applies at the group unit of analysis as well as for individuals. A group can acquire joint skills and shared understandings, but this can be distinguished from group knowledge artifacts, which have their origin in group processes, such as argumentation, perspective sharing or negotiation (ibid). The artifact nature of knowledge objects allows meanings to be shared - in the intersubjective world. It also allows the building of collaborative knowledge to be studied by CSCL researchers observing the evolving artifacts.

Whereas theories of individual learning often attribute a priority to the mental, as a source of meanings that are re-presented or ex-pressed in the communal world, the analysis of collaborative learning needs to prioritize the intersubjective meaning of shared artifacts. It is, for instance, in the formation of inscriptions in a joint problem space or postings in text chatwhich elicit and respond to each other - that meaning is originally formed. Resources constructed at the group unit of analysis are the prime mediators between individual understanding and community institutions in CSCL contexts (Stahl 2013b).

The term artifact entails that human knowledge is inscribed in a material object and that the object can be used as a meaning potential within a collaborative effort (Linell 2009). An important question raised in the five articles below is how the artifacts become aligned in the interactional activities. Productive learning events (Damsa 2014) can be activated in the interactions that align artifacts. Alignment (Goffman 1974; van de Sande and Greeno 2012) is an important term in CSCL since it provides analytic attention to how artifacts can support students in understanding conceptual connections within a theoretical system. By this we mean that students can connect several concepts into a partial understanding of a phenomenon (diSessa 2006). Alignment in qualitative studies means that one analyzes how artifacts become used and how they can scaffold student development. In quantitative studies, one tests hypotheses in order to establish statistically significant results, which indicate that some artifacts are more productive than others in collaborative efforts.

The foundational role of artifacts in CSCL has been extensively discussed recently in ijCSCL (Furberg et al. 2013; Halatchliyski et al. 2014; Öner 2013; Overdijk et al. 2014; Stahl 2013a; Stahl et al. 2014a, b; Timmis 2014; Zemel and Koschmann 2013). The following articles address these issues in different and suggestive ways. 


\section{Alignment of augmented-reality artifacts}

In their article proposing a theory of liminal blends, Noel Enyedy, Joshua A. Danish and David DeLiema argue for a new theoretical framework that can explain the relationship between conceptual and material resources. The idea of liminal blends comes from conceptual-blend theory, which emphasizes that in order to perform specific actions we need to combine and blend resources from different source domains into an emerging hybrid conceptual space, and that these resources cannot be found in each of the source domains taken by themselves. While conceptual-blend theory was developed to describe how individuals create emerging conceptual blends, the authors of this article extend and reformulate the theory. Through their socio-cultural and distributed view of cognition and learning, they create a new unit of analysis for explaining how conceptual blends can be enacted.

In this study, the new artifact formed is an augmented-reality environment, which young students help to define, enact as usable and reflect upon as they interact in their physical classroom. The empirical basis for the article comes from the project Learning Physics through Play. Here, a new design with augmented reality is tested with first and second graders. In a previous study (Enyedy et al. 2012), the authors showed that students improved their understanding of concepts like force and motion, through a pre-/post-test design.

In the article, a careful interaction analysis is performed to test the liminal-blend framework. It documents how the students concretely form intersubjective meanings associated with the augmented-reality artifacts through their bodily behavior in the augmented physical world. Alignment of resources becomes the most important process. To align resources from augmented reality and the physical interaction over time, the classroom technology evolves emerging properties that have the potential to transform the students' understanding of the concepts they work with. As the students work in their complex social space, they bring together the conceptual resources, their bodily movements and the emerging resources that become mobilized through the social interaction. Shared meaning is constructed through the enactment of the artifacts in the classroom, and is subsequently available for individual and collaborative reflection.

This study has implications for how we reason about human learning, how we study collaborative interaction in an augmented-reality environment and how we design such a CSCL environment. This is a novel contribution to the development of liminal-blend theory, which avoids the split between conceptual and material structures in the world, associated with previous versions of the theory.

\section{Assessment of informational artifacts}

The article by Andrea Forte introduces a new area to CSCL research, bringing in the analysis of information-seeking behaviors from information science to understand new technologically enabled genres of literacy. She investigates high school students' information assessment practices as part of an activity in which the students took part in building a collaborative online textual artifact. Here, the artifacts formed are texts generated by the students. The study stretches over a 2-year period and makes use of multiple methods, including classroom observations, interviews and stimulated recall about how students become involved in the consumption and production of texts relevant to a topic. As technology innovations from CSCL research, evolution of social media and design of collaborative environments make possible new forms of information artifacts, we need to study how people understand these 
media, contribute to them and engage in intersubjective meaning making mediated by these new kinds of artifacts.

One important finding is that although the design of the activities is aimed at supporting open collaboration, specific established school norms still become activated. Students have a long history of doing schoolwork, which means that they frame tasks in institutionally sanctioned ways. However, students not only perform their action in accordance with historical norms, they also expand their activities and take certain responsibilities for collective knowledge building, because creating conditions for students to engage in collaborative production efforts creates new learning opportunities. Students become exposed to basic questions about what types of information can be trusted, what the limits of that information are, what their responsibility is for the information produced, and what collective responsibility they share.

This study contributes a more nuanced discussion about what we mean by informationliteracy skills and practices and more generally how we understand and explain 21st century skills in CSCL settings. It explores how students might interact with, contribute to and make sense of the increasingly complex informational artifacts, which combine traditional heritages and virtual opportunities.

\section{Knowledge representation in exploratory artifacts}

In their article on an interactive genetics-visualization exhibit, Pryce Davis, Michael Horn, Florian Block, Brenda Phillips, E. Margaret Evans, Judy Diamond and Chia Shen analyze museum visitors' interactions around a multi-touch tabletop exhibit called DeepTree. This article continues the ijCSCL theme of tabletop interfaces (Dillenbourg and Evans 2011; Martinez-Maldonado et al. 2013). The genetics environment was designed with a conceptual focus on evolution and common ancestral descent. Museums as social and historical institutions can create experiences for young people and students that involve access to specific forms of knowledge. In this study, the authors describe how dyads of visitors interact with a multi-touch table in order to coordinate their action and to co-create meaning.

A core feature in the design of the environment is its advanced visualization techniques. The paper's qualitative analysis shows how the dyads work and interact with this technological artifact. The results from the analysis show four patterns of interaction. The article uses the metaphor of paddlers to explain the results. When inexperienced paddlers try to work together, certain coordination problems can be expected. The coordination problem related to the mechanical goal is of a different sort than that of the conceptual goal. The mechanical goal in this environment is related to the direction of exploration activities, while the conceptual goals move the coordination problem to the surrounding scientific terrain. One important finding is that the design itself provides limited support for students to move toward working with the conceptual goals involving understanding evolutionary science. To work with conceptual goals is part of moving beyond sequences of directed tasks.

At the level of experience, the design makes it possible for students to act with representations of knowledge that are unique. This can give them insight about the core concepts of human evolution. For citizens in our society to gain such experience has a value in itself, and they can become motivated to ask questions about different forms of knowledge. Using advanced artifacts - like this sophisticated tabletop exhibit — to interact can make specific aspects of the knowledge involved more transparent for students in their learning processes. 


\section{Networked artifacts for second-language learning}

Yun Wen, Chee-Kit Looi and Wenli Chen investigate how networked second-language learning can take place across multimedia settings. They focus on the intellectual interaction in groups through what they call diachronic development of understanding across members of a group. A representational tool, Group Scribbles (Song and Looi 2012), which includes private and public/group spaces, mediates the learning activities across multiple media settings, supporting the building and refinement of knowledge artifacts that both use and reflect on English. The students who form part of this study are eighth graders who speak English as a second language, but come from diverse language backgrounds (Chinese, Malay and Tamil).

The statistics used show variations in group interaction in different media spaces and within the face-to-face setting. The results show that the groups use the tool differently, depending upon their task and their linguistic competence. When the tool serves the function of referencing, the learning activities became less cognitively demanding; however, when the tool serves the function of promoting synergy, realizing parallels, or prompting noticing, the cognitive activities became more productive for language learning. The pedagogical design that stimulates the students to externalize, building upon and pursuing consensus, creates productive interactions between the students.

The study demonstrates again that in order to create productive CSCL environments, we need to take into account the interdependencies between students and artifacts. The analysis draws on recent theoretical insights about the relationship of artifact affordances to their usage and about representational acts to their mediation by specialized technologies (Damsa 2014; Overdijk et al. 2014; Ritella and Hakkarainen 2012; Suthers et al. 2010). It applies these perspectives to analyze how the students enact Group Scribbles - both individually and collaboratively - to articulate arguments and to improve their use of English as they refine their inscriptions in the technological medium.

\section{New research artifacts}

All the articles in this issue raise important points about how different forms of artifacts, tools and resources with specific features can stimulate productive collaborative learning. The artifacts are new formations of knowledge and formats for collaboration. Artifacts play many roles in CSCL settings: as mediating technologies, as instructional resources, as student work products and as interaction texts. The studies emphasize that, in order to advance the field of $\mathrm{CSCL}$, the detailed analysis of artifacts in interaction is of central concern.

Some of these issues will undoubtedly be discussed at the up-coming CSCL 2015 conference (isls.org/cscl2015). We look forward to seeing you there in Gothenburg.

\section{References}

Arvaja, M. (2012). Personal and shared experiences as resources for meaning making in a philosophy of science course. International Journal of Computer-Supported Collaborative Learning, 7(1), 85-108.

Damsa, C. I. (2014). The multi-layered nature of small-group learning: Productive interactions in object-oriented collaboration. International Journal of Computer-Supported Collaborative Learning, 9(3), 247-281.

Dillenbourg, P., \& Evans, M. (2011). Interactive tabletops in education. International Journal of ComputerSupported Collaborative Learning, 6(4), 491-514.

diSessa, A. A. (2006). A history of conceptual change research: Threads and fault lines. In R. K. Sawyer (Ed.), The Cambridge handbook of the learning sciences (pp. 265-281). New York: Cambridge University Press. 
Enyedy, N., Danish, J. A., Delacruz, G., \& Kumar, M. (2012). Learning physics through play in an augmented reality environment. International Journal of Computer-Supported Collaborative Learning, 7(3), 347-378.

Furberg, A., Kluge, A., \& Ludvigsen, S. (2013). Student sensemaking with science diagrams in a computerbased setting. International Journal of Computer-Supported Collaborative Learning, 8(1), 41-64.

Goffman, E. (1974). Frame analysis: An essay on the organization of experience. New York: Harper \& Row.

Halatchliyski, I., Moskaliuk, J., Kimmerle, J., \& Cress, U. (2014). Explaining authors' contribution to pivotal artifacts during mass collaboration in the wikipedia's knowledge base. International Journal of ComputerSupported Collaborative Learning, 9(1), 97-115.

Hutchins, E. (2005). Material anchors for conceptual blends. Journal of Pragmatics, 37(10), 1555-1577.

Linell, P. (2009). Rethinking language, mind, and world dialogically: Interactional and contextual theories of human sense-making. Charlotte: Information Age Publishing.

Lonchamp, J. (2012). An instrumental perspective on CSCL systems. International Journal of ComputerSupported Collaborative Learning, 7(2), 211-237.

Martinez-Maldonado, R., Dimitriadis, Y., Martinez-Mones, A., Kay, J., \& Yacef, K. (2013). Capturing and analyzing verbal and physical collaborative learning interactions at an enriched interactive tabletop. International Journal of Computer-Supported Collaborative Learning, 8(4), 455-485.

Öner, D. (2013). Analyzing group coordination when solving geometry problems with dynamic geometry software. International Journal of Computer-Supported Collaborative Learning, 8(1), 13-39.

Overdijk, M., van Diggelen, W., Andriessen, J., \& Kirschner, P. A. (2014). How to bring a technical artifact into use: A micro-developmental perspective. International Journal of Computer-Supported Collaborative Learning, 9(3), 283-303.

Ritella, G., \& Hakkarainen, K. (2012). Instrumental genesis in technology-mediated learning: From double stimulation to expansive knowledge practices. International Journal of Computer-Supported Collaborative Learning, 7(2), 239-258.

Scardamalia, M., \& Bereiter, C. (2014). Knowledge building and knowledge creation: Theory, pedagogy and technology. In K. Sawyer (Ed.), Cambridge handbook of the learning sciences (2nd ed.). Cambridge: Cambridge University Press.

Song, Y. J., \& Looi, C. K. (2012). Linking teacher beliefs, practices and student inquiry-based learning in a CSCL environment: A tale of two teachers. International Journal of Computer-Supported Collaborative Learning, 7(1), 129-159.

Stahl, G. (2012). Traversing planes of learning. International Journal of Computer-Supported Collaborative Learning, 7(4), 467-473.

Stahl, G. (2013a). Learning across levels. International Journal of Computer-Supported Collaborative Learning, $8(1), 1-12$.

Stahl, G. (2013b). Translating Euclid: Designing a human-centered mathematics. San Rafael, CA: Morgan \& Claypool Publishers. Web: http://GerryStahl.net/elibrary/euclid.

Stahl, G., Cress, U., Law, N., \& Ludvigsen, S. (2014a). Analyzing the multidimensional construction of knowledge in diverse contexts. International Journal of Computer-Supported Collaborative Learning, $9(1), 1-6$.

Stahl, G., Ludvigsen, S., Law, N., \& Cress, U. (2014b). CSCL artifacts. International Journal of ComputerSupported Collaborative Learning, 9(3), 237-245.

Suthers, D. D., Dwyer, N., Medina, R., \& Vatrapu, R. (2010). A framework for conceptualizing, representing, and analyzing distributed interaction. International Journal of Computer-Supported Collaborative Learning, $5(1), 5-42$.

Timmis, S. (2014). The dialectical potential of cultural historical activity theory for researching sustainable CSCL practices. International Journal of Computer-Supported Collaborative Learning, 9(1), 7-32.

van de Sande, C. C., \& Greeno, J. G. (2012). Achieving alignment of perspectival framings in problem-solving discourse. Journal of the Learning Sciences., 21(1), 1-44.

Zemel, A., \& Koschmann, T. (2013). Recalibrating reference within a dual-space interaction environment. International Journal of Computer-Supported Collaborative Learning, 8(1), 65-87. 